
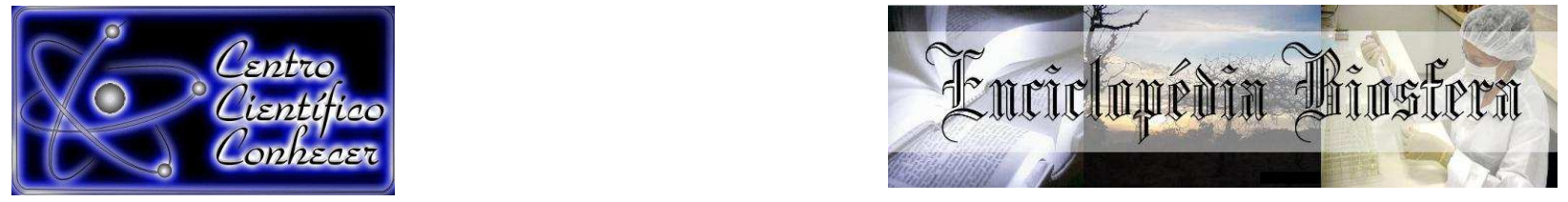

\title{
FITOTERÁPICOS AMAZÔNICOS: COPAÍBA NO TRATAMENTO DE FERIDAS CUTÂNEAS
}

Carolina Couto Barquete ${ }^{1}$, Adriane de Souza Belfort ${ }^{2}$, Joelma de Faria Santos ${ }^{3}$, Soraia Figueiredo de Souza ${ }^{4}$

${ }^{1}$ Médica Veterinária, mestranda na Universidade Federal do Acre, UFAC (carolvetufac@gmail.com), Acre - Brasil

${ }^{2}$ Médica Veterinária, mestranda na Universidade Federal do Acre, UFAC, Acre Brasil

${ }^{3}$ Graduanda em Medicina Veterinária, Universidade Federal do Acre, Acre, Brasil

${ }^{4}$ Professora Doutora do Curso de Bacharelado em Medicina Veterinária e do

Programa de Pós-graduação em Sanidade e Produção Animal Sustentável na

Amazônia Ocidental, Universidade Federal do Acre, Acre, Brasil

Recebido em: 02/10/2017 - Aprovado em: 21/11/2017 - Publicado em: 05/12/2017 DOI: 10.18677/EnciBio 2017B32

\begin{abstract}
RESUMO
Feridas cutâneas são uma interrupção na continuidade de um tecido corpóreo, geralmente causadas por trauma, e se caracterizam como uma das principais afecções físicas dos animais. Plantas medicinais são utilizadas como método terapêutico, dessa e demais condições patológicas, por séculos em populações tradicionais, demonstrando o potencial farmacêutico dos fitoterápicos. O emprego desses agentes pode minimizar os custos, aumentar eficácia e garantir a sustentabilidade dos protocolos desenvolvidos através dessa terapia alternativa. $O$ tratamento de feridas, e a cicatrização cutânea são práticas de grande casuística na medicina veterinária, o que fomenta o interesse na otimização das tecnologias utilizadas com esse objetivo. Devido à biodiversidade da região amazônica, princípios ativos de diferentes plantas medicinais têm sido estudados como possíveis cicatrizantes. Dentre as espécies conhecidas, a copaíba destaca-se como uma das mais relevantes para esse objetivo. Portanto, essa revisão objetiva expor os fitoterápicos presentes na Amazônia destinados ao tratamento de feridas cutâneas, demonstrando, em especial, os benefícios já conhecidos da copaíba.
\end{abstract}

PALAVRAS-CHAVE: cicatrização de feridas, pele, plantas medicinais.

\section{AMAZON PHYTOTERAPICS: COPAIBA IN THE TREATMENT OF SKIN WOUNDS}

\begin{abstract}
Skin wounds are an interruption in the continuity of a tissue, generally caused by trauma, and one of the major physical issues of animals. Medicinal plants are used as a therapeutic method, as a solution to this and other pathological conditions, for centuries in traditional populations, demonstrating the pharmacological potential of herbal medicines. The use of these agents can minimize costs, increase effectiveness, and ensure the sustainability of the protocols developed through this
\end{abstract}


alternative therapy. The treatment of skin wounds, and wound healing are practices of great casuistry in veterinary medicine, stimulating interest in the optimization of the technologies used for this purpose. Due to the biodiversity of the Amazon region, active principles of different medicinal plants have been studied as healing enhancer. Among the known species, copaiba stands out as one of the most relevant for this purpose. Therefore, this review aims to expose the phytotherapics present in the Amazon for the treatment of cutaneous wounds, highlighting the already known benefits of copaiba.

KEYWORDS: wound healing, skin, medicinal plants.

\section{INTRODUÇÃO}

As plantas medicinais apresentam grande significância pelo fato serem usadas como agentes terapêuticos por cerca de quatro bilhões de pessoas, pertencentes a populações indígenas, que as incorporam em seus cuidados básicos de saúde, de maneira empírica, devido a acessibilidade limitada dos demais recursos à essa parcela da população mundial (PAZYAR et al., 2014).

Dentre esses fitoterápicos, existe uma tendência para o desenvolvimento da área destinada para o tratamento de feridas ou doenças da pele, pois cerca de um terço desses produtos apresentam esse objetivo, o que diverge da medicina tradicional, que possui como representantes dessa categoria apenas $3 \%$ das drogas modernas. Logo, esse interesse fomenta o desenvolvimento de diversos estudos para a evolução do uso desses produtos naturais (BUDOVSKY et al., 2015).

As feridas são definidas como quebra da continuidade normal de estruturas, com origem física, química, microbiológica ou imunológica. Existem diversos métodos para suas classificações, de acordo com sua apresentação clínica, contaminação ou tempo do processo patológico, e o tratamento dessas é uma prática frequente, com a cicatrização completa como principal resultado esperado na clínica médica (MITTAL et al., 2013).

A cicatrização de feridas é um processo bioquímico dinâmico, que envolve a coordenação precisa de diversas vias: fisiológica; imunológica; celular (MASSONMEYERS et al., 2013). Ocorre nesse período, a inter-relação entre as células, seu microambiente e a matriz extracelular, sendo a partir disso determinado o direcionamento para a diferenciação, proliferação das células ou a permanência dessas em estado quiescente. $O$ processo cicatricial divide-se em três fases distintas, inflamatória, proliferativa e de remodelação (MAVER et al., 2015).

Os eventos são iniciados logo após a injúria e podem se estender por meses, durante os quais o tecido busca, através da produção de colágeno e matriz proteica, retornar ao seu aspecto inicial. Logo, o objetivo do tratamento das feridas é a redução do tempo envolvido no processo, além de evitar consequências como as cicatrizes (ADIELE et al., 2014).

Apesar de muitos avanços na área o tratamento de feridas crônicas ainda possui restrições, pois apesar de opções terapêuticas como limpeza, debridamento, fármacos antibióticos e agente cicatrizantes, a eficácia restrita e o custo proibitivo presente nessas técnicas (MASSON-MEYERS et al., 2013), são fatores que devem ser levados em consideração quando se analisa tratamentos veterinários.

Como forma de analisar a eficácia do uso dos fitoterápicos, vem sendo desenvolvidos estudos avaliando suas propriedades terapêuticas, como por exemplo, o uso de Copaifera sp. (Figura 1), Carapa sp. (Figura 2) e Piper sp. (Figura 
3) no tratamento de diversas afecções. A validez dessas linhas de pesquisa se torna evidente quando se analisam relatos de que quatro bilhões de pessoas utilizam plantas como medicamentos globalmente, dado que outros métodos são acessíveis (DORAI, 2012).

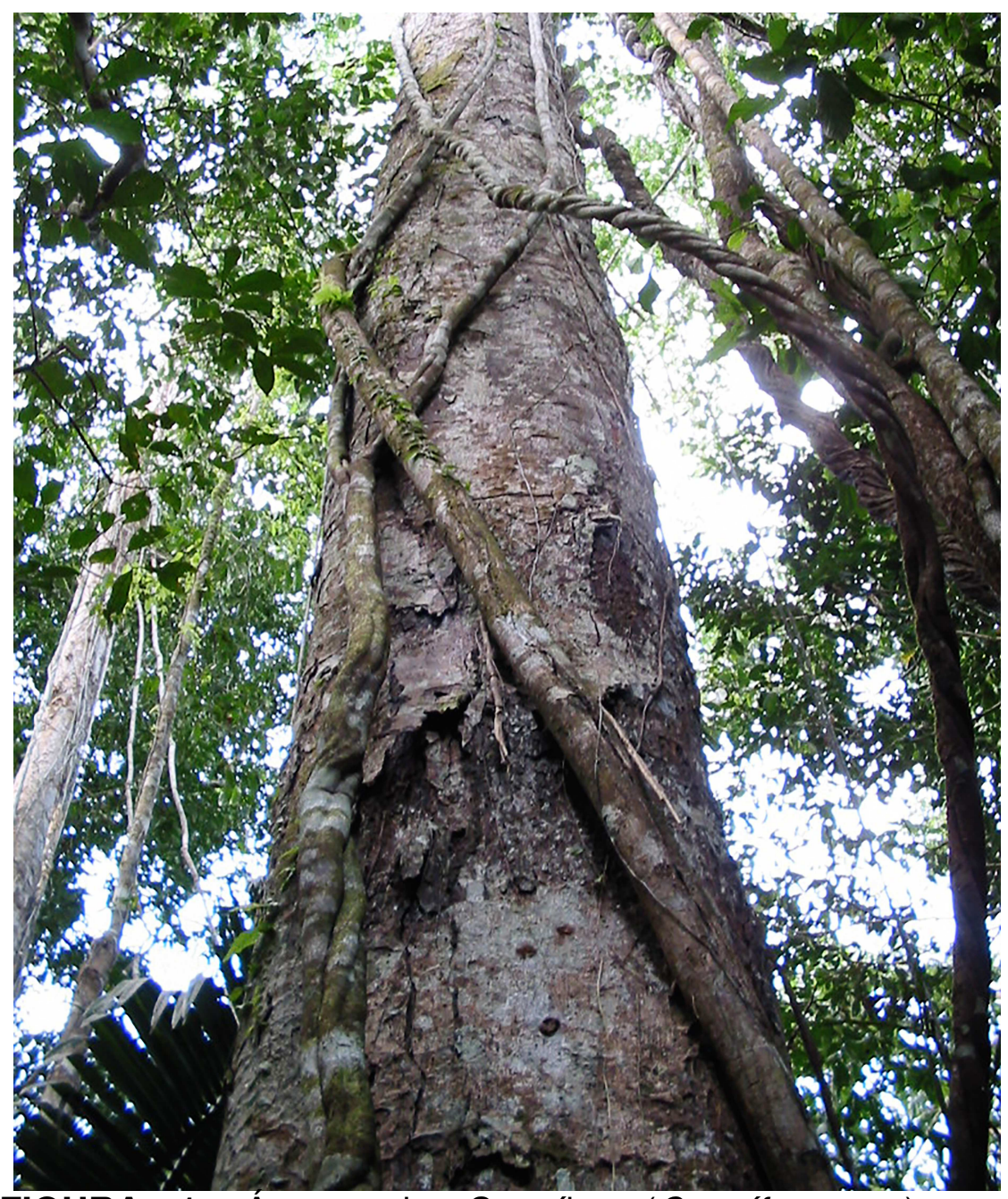

FIGURA 1. Arvore de Copaíba (Copaífera sp.) em condições de ambiente natural. Fonte: modificada de <http://1.bp.blogspot.com/-

Uf1p HPQ5ZY/TzacbIUNpMI/AAAAAAAAAC8/V36-

bURX.SS/s1600/Copaiba.JPG>. 


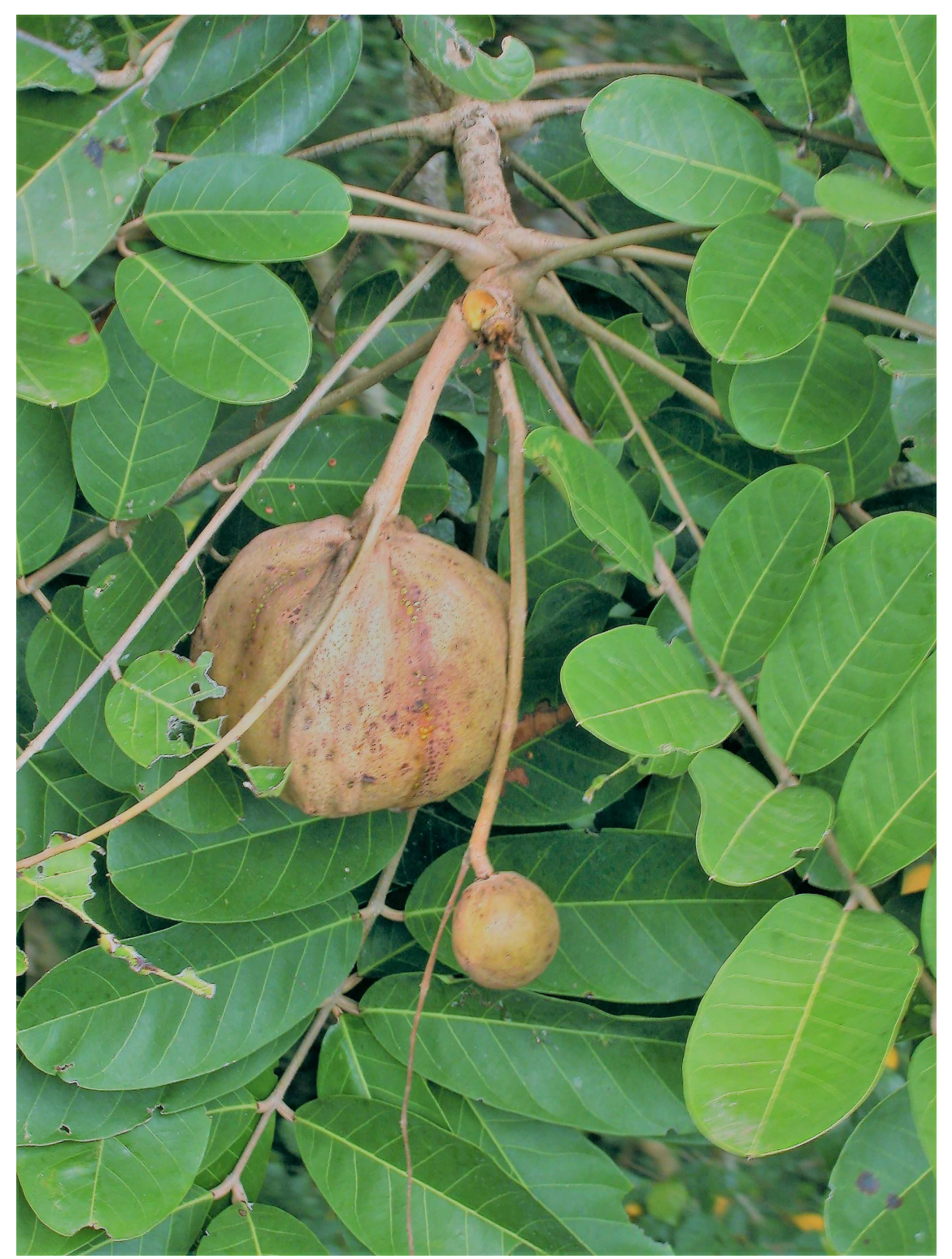

FIGURA 2. Andiroba (Carapa sp.), em detalhe folhas e sementes.

Fonte: modificada de <http://www.elhogarnatural.com/Arboles/carapa2.jpg>. 


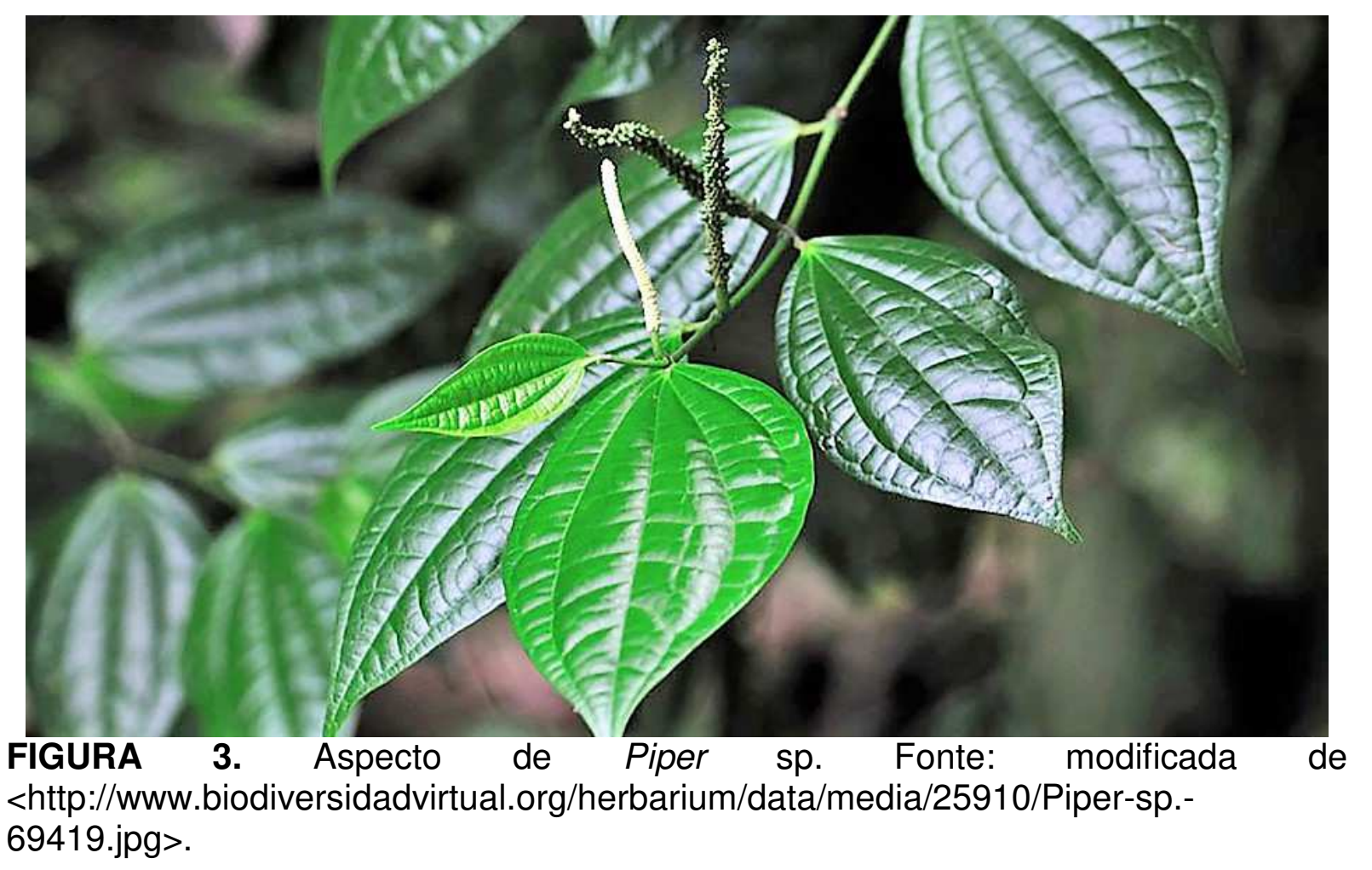

De acordo com Ghosh e Gaba (2013) os principais efeitos realizados por fitoterápicos na cicatrização de feridas são ação antimicrobiana, antioxidantes, e promoção da mitose, angiogênese, aumento da produção colágena e maior síntese de DNA, qualidades desejáveis em qualquer substância cicatrizante. Dado que a Amazônia ocupa $40 \%$ do território nacional e cerca de $20 \%$ de sua área ainda se encontra preservada, estima-se haver nessa biodiversidade, apenas para plantas de valor econômico e social, cerca de 800 espécies, sendo centenas dessas utilizadas como plantas medicinais (SANTOS et al., 2014).

Nesse estudo objetivou-se realizar uma revisão de literatura sobre os fitoterápicos da Amazônia, em especial as ações terapêuticas da copaíba, e seus efeitos na cicatrização de feridas, promovendo o conhecimento nessa área de grande valor geopolítico e ainda pouco explorado.

\section{DESENVOLVIMENTO}

Cicatrização de Feridas

A pele é uma barreira natural contra o meio externo e exerce diversas funções protetoras no organismo. Quando essa proteção é quebrada por lesões agudas ou crônicas, um processo de diversas etapas, dinâmico inicia-se levando à cicatrização parcial do tecido e retorno da função protetora da pele (AKBIK et al., 2014). O objetivo desse processo é obter homeostase e integridade do tecido, o que se torna possível através de quatro etapas simultâneas: hemostasia; inflamação; fase proliferativa; fase de remodelamento (Figura 4) (MAVER et al., 2015). 


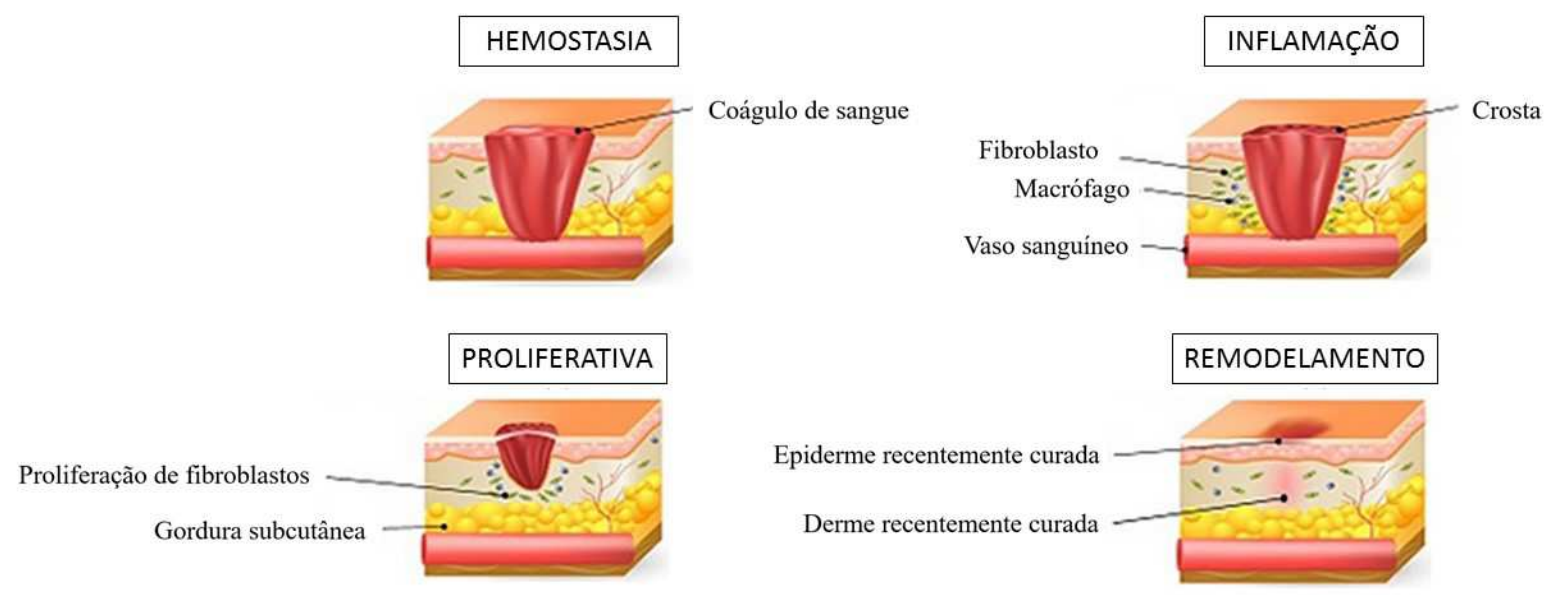

FIGURA 4. Esquema representativo das etapas do processo cicatricial. FONTE: modificada de <http://www.celerowoundhealing.com/uploads/9/4/8/8/9488042/9395478.jpg?530>.

O objetivo desse processo é obter homeostase e integridade do tecido, o que se torna possível através de quatro etapas simultâneas: hemostasia; inflamação; proliferativa; remodelamento (MAVER et al., 2015). A hemostasia ocorre logo após a lesão e constitui-se de agregação de plaquetas e formação do coágulo sanguíneo, que servirá de matriz extracelular provisória para a migração de células (AKBIK et al., 2014). Inicialmente, os vasos sanguíneos contraem em resposta a lesão, porém eventualmente retornam ao estado inicial. As plaquetas bloqueiam o sangramento em seguida, além de liberarem substâncias vasoconstritoras que favorecem 0 processo.

Nesse mesmo momento ativa-se a cascata de coagulação, que por fim irá estimular a formação de trombina, processo que auxilia na transformação do fibrinogênio em fibrina. A rede de fibrina é responsável por enrijecer o tampão plaquetário e tornar o coágulo estável (SLATTER, 2007). Esse recrutamento de plaquetas é dito como consequência da liberação de prostaglandinas pela lesão. Após essa agregação e adesão as mesmas liberam fatores quimiotáticos, que possuem funções distintas no processo cicatricial.

Os mastócitos presentes nos vasos sanguíneos da região lesada liberam histamina, fator de necrose tumoral, leucotrienos e citocinas (GHOSH; GABA, 2013), que funcionam como sinalizadores para a migração de leucócitos, dando início à fase de inflamação.

A segunda fase ou fase inflamatória, se inicia imediatamente após a lesão e geralmente dura entre 24 e 48 horas e pode persistir até duas semanas, em alguns casos. Nesta fase ocorrem eritema, edema e calor associado com a dor, bactérias e os detritos são fagocitadas por macrófagos, que liberam fator derivado de plaquetas (PDGF), fator de crescimento transformador beta (TGF- $\beta$ ), fator de crescimento de fibroblastos beta ( $\beta-F G F)$, fator de necrose tumoral alfa (TNF- $\alpha$ ), e interleucinas 1 e 6 (IL-1 e IL-6) que auxiliam na próxima fase na fase proliferativa.

As últimas células envolvidas nesse processo, os linfócitos, são essenciais na produção de IL-2, que recruta os fibroblastos (PAZYAR et al., 2014). Os fagócitos realizam a limpeza de partículas estranhas ao corpo, bem como liberam citocinas ENCICLOPÉDIA BIOSFERA, Centro Científico Conhecer - Goiânia, v.14 n.26; p.366 2017 
responsáveis pela migração e proliferação de fibroblastos, envolvidos no processo final da cicatrização. Essa fase possui desenvolvimento completo em quatro dias (SLATTER, 2007).

A fase proliferativa tem duração média de dois dias até três semanas, após a fase inflamatória, tem como principais características, a formação de novos vasos sanguíneos (angiogênese), com função de nutrir o novo tecido, e a síntese de matriz extracelular como deposição de colágeno, formação de tecido de granulação, e contração da ferida. Estima-se que o início desse processo ocorre logo após a limpeza dos debris (BUDOVSKY et al., 2015).

Os fibroblastos, principais responsáveis pelas ações desse momento, migram para o local da ferida e secretam a matriz inicial de colágeno, onde a regeneração dérmica irá ocorrer. Inicialmente o colágeno secretado é do tipo III, que posteriormente será degradado e substituído, pelo colágeno tipo I, uma forma mais rígida da substância, na fase de maturação, na qual o colágeno é entrelaçado e organizado, promovendo máxima rigidez ao no tecido. Na fase final da epitelização, os ceratinócitos se diferenciam formando uma camada externa protetora (PAZYAR et al., 2014).

O final da cicatrização ocorre na fase de remodelamento, esta possui duração de três semanas a dois anos, envolvendo objetivos como a reestruturação do colágeno e a formação do tecido cicatricial (EPSTEIN et al., 1999). A resistência à tração do tecido é aumentada devido ao entrelaçamento intermolecular do colágeno através da hidroxilação dependente de vitamina C. A cicatriz diminui e o tecido recupera cerca de $80 \%$ de sua tensão original (MITTAL et al., 2013). Diversos fatores influenciam a cicatrização, como, por exemplo, a dieta, pois a recuperação da lesão é um processo anabólico e necessita de energia e substratos provenientes de nutrientes, como a albumina, por exemplo.

A infecção do local lesionado também influencia negativamente esse processo (SLATTER, 2007). Os microrganismos mais comumente encontrados nesses casos são pertencentes à microbiota cutânea como: Staphylococcus aureus; Streptococcus pyogenes; Corynebacterium sp.; Escherichia coli; Pseudomonas aeruginosa, o que demonstra o papel crucial de antimicrobianos no tratamento de feridas (MITTAL et al., 2013).

Dentre os demais fatores deletérios para a reconstrução da barreira cutânea exemplifica-se: a má perfusão tecidual, que impede a chegada de substâncias essenciais para a resolução do quadro; anti-inflamatórios esteroidais, que reduzem a síntese de colágeno e proliferação fibroblástica; e quimioterápicos, conhecidamente inibidores de mitose. Características relacionadas ao indivíduo também possuem influência nesse mecanismo, como idade avançada e doenças sistêmicas, citandose como principal exemplo a Diabetes (MAVER et al., 2015).

\section{Principais Ações Farmacológicas no Tratamento de Feridas}

Os principais efeitos farmacológicos almejados no uso de fármacos ou outras substâncias cicatrizantes são o efeito anti-inflamatório, antioxidante, antimicrobiano e analgésico (VIEIRA et al., 2008; MAVER et al., 2015). 4A inflamação aguda embora essencial para o desencadeamento de ações a favor da reconstituição do tecido, quando prolongada pode impedir o processo cicatricial, retardando-o, e gerando dor na região lesada, portanto o uso de substâncias anti-inflamatórias se justifica como alternativa na tentativa de controlar tais alterações (SLATTER, 2007). 
Além de promover ferramentas intrínsecas do organismo para a reconstrução tecidual, faz-se necessário, no tratamento de feridas, controlar outros fatores que interfiram nesse processo. Portanto, a redução da carga bacteriana de um ferimento pode ser necessária para facilitar a cicatrização de feridas, bem como para reduzir a inflamação local e a destruição do tecido. Um agente ideal para a prevenção e controle de infecção da ferida deve destruir os patógenos diretamente ao mesmo tempo, estimular a atividade imune (MITTAL et al., 2013).

No entanto, quando se busca instituir um protocolo terapêutico que leve em consideração o bem-estar animal, evitando diversas consequências da dor, como automutilações e perda de produtividade, o uso de analgésicos também se torna indispensável para um tratamento de cicatrização de feridas eficaz.

Fitoterápicos no tratamento de feridas

Os principais efeitos dos princípios ativos dos extratos vegetais na cicatrização de feridas são: constituintes fitoquímicos que possuem atividade antimicrobiótica; atividade antioxidante removedora de radicais livres; componentes ativos que promovem atividade mitótica, que contribuem para a proliferação celular, angiogênese e aumento da produção de colágeno e síntese de DNA (BUDOVSKY et al., 2015).

A natureza química desses fitoterápicos varia conforme a espécie, os estudos realizados nesse campo buscam pesquisar alcaloides, carboidratos, glicosídeos, terpenóides, diterpenos, sesquiterpenos, fitosterol, compostos fenólicos, e vários tipos de taninos, proteínas, flavonoides, saponinas, ligninas, alcaloides e óleos essenciais (GHOSH; GABA, 2013).

Tomando-se como exemplo a Copaíba, observa-se em sua composição a presença de sesquiterpenos ( $80 \%$ do total) e diterpenos. Já a Andiroba, possui os ácidos graxos como componentes, dentre eles: oleico; palmítico; esteárico; linoleico. Além de flavonoides, triterpenos, esteroides, cumarinos e diglicerídeos (SANTOS et al., 2012).

Os componentes presentes em plantas medicinais possuem ações distintas e específicas, tomando-se como exemplo a função antimicrobiana, vê-se que essa é mais estudada em terpenos e terpenóides. Outra função observada nesses componentes é a ação adstringente, que promove a contração da ferida e aumento da taxa de epitelização, bem como as saponinas, que se incluem como agentes estimulantes desse mesmo processo (MASSON-MEYERS et al., 2013).

As propriedades antioxidantes são comumente citadas como a ação proporcionada pelos flavonoides, que inicialmente regulam a produção de ânions superóxidos e posteriormente aumento o fluxo sanguíneo da região lesada, promovendo a angiogênese, fatos que combinados reduzem os radicais livres na ferida (MITTAL et al., 2013). Esteróis e polifenóis são responsáveis pela cicatrização de feridas devido à sua eliminação de radicais livres e atividade antioxidante, que são responsáveis por reduzir a oxidação lipídica, reduzindo a necrose celular e melhorando a vascularização (BUDOVSKY et al., 2015).

Os taninos são conhecidos por promover a cicatrização de feridas, devido às suas propriedades adstringentes, essa função refere-se à capacidade desses metabólitos secundários dos vegetais em precipitar as proteínas da saliva, o que ocorre também com proteínas sanguíneas, bacterianas, parasitárias e enzimas. Possuem ação antimicrobiana, além de atuarem como sequestradores de radicais 
livres, através da formação de complexos com íons metálicos como o ferro, manganês, cobre, alumínio, que auxiliam nessa função antioxidante (KOBAYASHI et al., 2015). No entanto, os princípios ativos envolvidos na ação mitogênica dos fitoterápicos ainda não foram elucidados (BUDOVSKY et al., 2015).

\section{Plantas Medicinais da Amazônia}

De acordo com a Lista de Espécies da Flora Brasileira a Floresta Amazônica possui 40.989 espécies de plantas e fungos, sendo 18.932 desses endêmicos (FORZZA et al., 2010). Uma grande parcela dessa biodiversidade pode ser utilizada como fitoterápicos, e já possui uso medicinal tradicional, logo, essas vêm sendo estudadas como alternativas terapêuticas de baixo custo.

No estudo realizado por Santos et al. (2014) constatou-se, através de entrevistas com a população tradicional da Amazônia ocidental, que 53 espécies de plantas são utilizadas como medicinais, tais como Asteraceae, Euphorbiaceae, Fabaceae, Piperaceae e Amaranthaceae. No entanto, de todos os vegetais citados, apenas sete pertenciam à Amazônia, sendo esse fato explicado pela imigração de populações de outras regiões do país.

Seus principais usos são o tratamento de nefropatias, infecções, em especial Malária, inflamações e hipertensão arterial. Sendo esses remédios na maioria das vezes preparados através infusão e decocção. Dentre essas são citadas como aquelas que possuem propriedades cicatrizantes: Solidago chilensi (erva-lanceta), pertencente à região sul do Brasil, e Copaifera langsdorfii (Copaíba) (SANTOS et al., 2014).

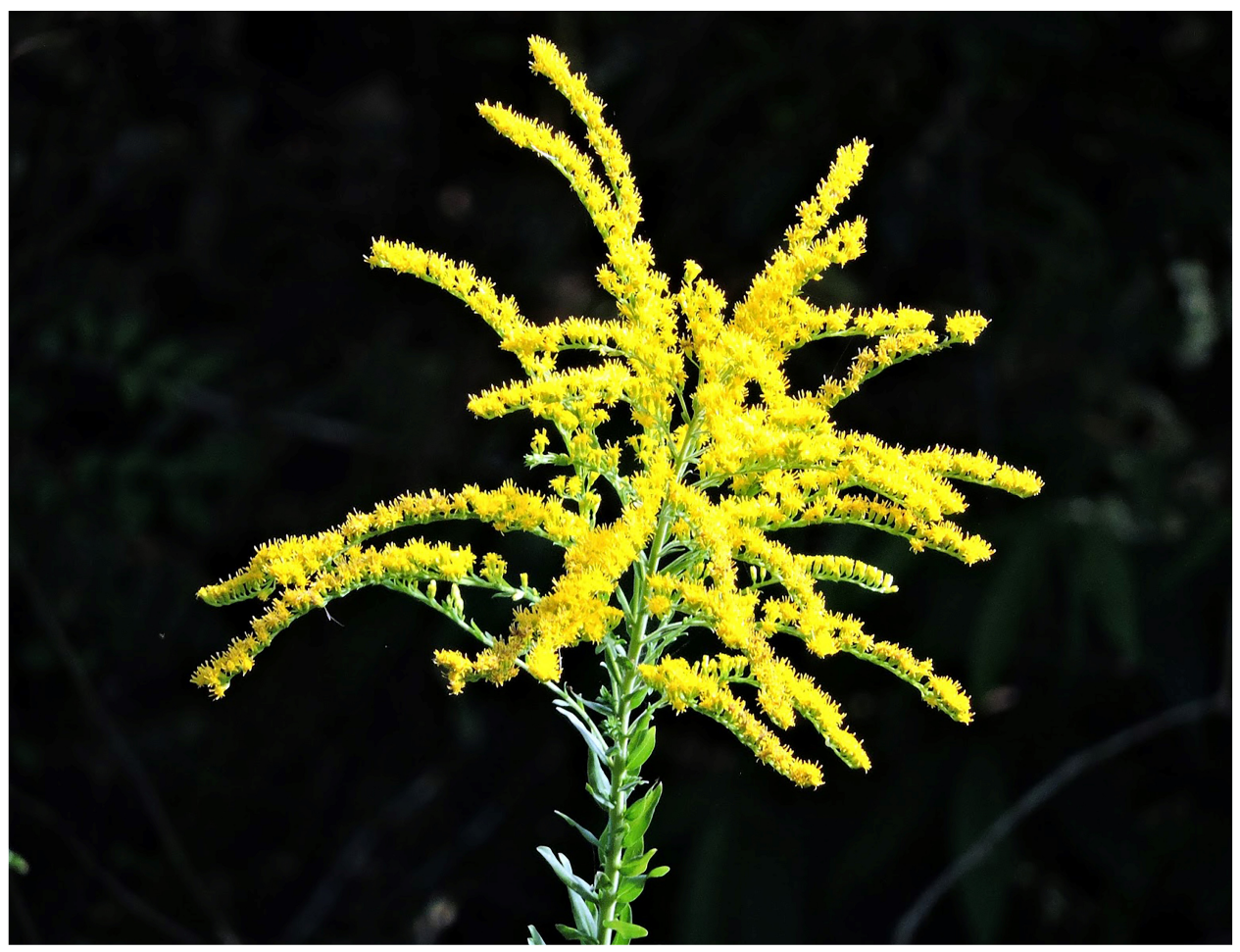

FIGURA 5. Inflorescência de Solidago chilensi.

Fonte: BUTZKE AGRíCOLA E FLORESTAL, (2017).

Outros fitoterápicos amazônicos também possuem ação satisfatória na cicatrização de feridas, como, por exemplo, a Andiroba (Carapa guaianensis) que 
possui uso tradicional na América do Sul como analgésico, anti-inflamatório, antialérgico, antibiótico, antiparasitário e antineoplásico (SANTOS et al., 2012).

No estudo de Kobayashi et al. (2015) pesquisou-se o uso de Libidibia ferria no tratamento de feridas, dado que em estudo etnoveterinário foi constatado o uso tradicional, da infusão no álcool desse vegetal no tratamento de feridas. Os resultados demonstram que essa planta pode ser utilizada, sem prejuízos à cicatrização tecidual, mesmo quando comparada ao emprego de um protocolo terapêutico tradicional. Sugere-se a composição de fitoterápico seja principalmente de tanino, fenóis e quinonas, o que explicaria sua ação cicatrizante, pois esses agentes químicos apresentam propriedades adstringentes e antioxidantes, e mais recentemente também estão sendo associados a efeitos antimicrobianos.

Outros fitoterápicos com uso potencial na cicatrização de feridas são aqueles pertencentes ao gênero Piper, sendo as espécies Piper hispidum Sw., Piper anonifolium Kunth, e Piper aleyreanum C. DC., comumente encontradas na Amazônia brasileira. Estudos de Silva et al. (2014) pesquisaram as composições de cada uma dessas espécies, dado seu uso como plantas medicinais nessa região. Constatou-se que o principal princípio ativo encontrado nesses exemplares foi o sesquiterpeno, o que evidencia a correlação dessas plantas, em especial a $P$. aleyreanum com ações anti-inflamatória, dado suas propriedades antioxidantes.

\section{A Copaíba Como Agente Cicatrizante}

Dentre as plantas medicinais amazônicas, a Copaíba (Copaifera spp.) destaca-se como fitoterápico cicatrizante, dado suas propriedades adstringentes e anti-inflamatórias. Apesar de ter uso principalmente no tratamento de feridas e como antisséptico urinário (MASSON-MEYERS et al., 2013), diversos outros usos são associados com esse vegetal, por exemplo, o tratamento de doenças de trato respiratório superior e inferior, úlceras (STUPP et al., 2008), endometriose (SILVA et al., 2015), afecções de sistema reprodutor através de creme vaginal (LIMA et al., 2011), como substituto à clorexidina em profilaxia dentária em cães (PIERI et al., 2014), além de ser utilizada como anti-tétano, anti-tumor (SANTOS et al., 2012), anti-leishmania e larvicida (LEANDRO et al., 2012).

Estudos que relacionam o emprego da copaíba como fitoterápico cicatrizante mostram uma variação de resultados, como os obtidos por Estevão et al. (2013), que avaliaram flaps cutâneos, e provaram que o uso de óleo de copaíba a 10\%, diretamente aplicado sobre a lesão, foi benéfico para a cicatrização, diminuindo a necrose e acelerando o processo de reparação. A mesma vantagem foi encontrada por Masson-Meyers et al. (2013), que diferente da maioria dos trabalhos com o uso de Copaifera spp. no tratamento de feridas cutâneas, desenvolveram um creme à base de óleo de Copaíba à 10\%, com base em estudos prévios que encontraram essa concentração ótima. Resultando em aumento na velocidade do processo, e na quantidade de colágeno envolvida na resolução da lesão.

No entanto Vieira et al. (2008) observaram piora na cicatrização de feridas, com presença de corpo estranho, quando utilizado o óleo de copaíba in natura no protocolo terapêutico, o que evidencia a questão de que a forma farmacêutica utilizada nesses experimentos pode ser um fator de influência do resultado final obtido nos experimentos. Apesar de o gênero possuir diversas espécies, os principais resultados positivos no uso como cicatrizante são aqueles que utilizam a espécie Copaifera langsdorffii em sua metodologia. 
Além dos estudos relacionados aos efeitos cutâneos desse vegetal, foram evidenciadas em outras linhas de pesquisa, como o estudo de Silva et al. (2015) que avaliou os efeitos do fitoterápico na reparação óssea, com administração de óleo de copaíba in natura, não evidenciando diferenças em relação ao protocolo tradicional com meloxicam. Já no experimento de Dias-da-Silva et al. (2013) observou-se um efeito benéfico no uso desse produto em alvéolo dentário na cicatrização do osso, nas administrações tópica e sistêmica, causando, porém, efeitos deletérios em tecido conectivo. Ainda sobre o uso de copaíba em odontologia veterinária, Dias et al. (2015) constataram que o uso de pasta de hidróxido de cálcio $P$. A. associada à óleo de copaíba não apresentou diferenças, quando comparada ao padrão (associação da pasta com solução salina estéril), tendo ambas os mesmos resultados sobre a formação de ponte dentária, além de apresentarem efeito antimicrobiano semelhantes.

Dentre as partes utilizadas desse vegetal, o óleo extraído de seu tronco é a fração mais significativa, sendo utilizada na maioria dos estudos encontrados, porém pesquisadores buscam ampliar o seu uso, através de pesquisas com o extrato das folhas, que apresentou propriedades anti-inflamatórias e neuroprotetoras em ratos submetidos artificialmente a acidente vascular cerebral (BOTELHO et al., 2015), enquanto Stupp et al. (2008) avaliaram possíveis usos para as sementes de Copaifera langsdorffii, encontrando em sua composição cumarina e xiloglicanos, que podem ter possível emprego na indústria cosmética.

As características oferecidas por esse fitoterápico são proporcionadas por seus principais componentes, sesquiterpenos e diterpenos, sendo o primeiro quase $90 \%$ da constituição vegetal. As propriedades cicatrizantes relacionadas à essa planta, como o poder anti-inflamatório são fornecidas pelos sesquiterpenos, enquanto que as características antimicrobianas, que auxiliam a reparação de lesões, são originadas pelos diterpenos (LEANDRO et al., 2012).

Desafios no uso de plantas medicinais amazônicas

Apesar das visíveis vantagens no uso de fitoterápicos, com o objetivo de acelerar a cicatrização de feridas, algumas limitações ao seu uso devem ser ressaltadas, como conhecimento limitado sobre as plantas utilizadas no tratamento de feridas; carência de ensaios clínicos com o uso desses vegetais; e pouca investigação sobre seus efeitos no processo cicatricial. Essas deficiências são evidenciadas na incapacidade dos estudos de compreender em sua totalidade os mecanismos terapêuticos dos componentes vegetais (PAZYAR et al., 2014).

Um fator que agrava o conhecimento sobre essas plantas é a complexidade dos componentes químicos e dos estudos fitoquímicos, devido a ampla variação dentre os indivíduos e seus produtos, o que impede a observação das alterações histológicas e histoquímicas causadas por esses princípios ativos com uniformidade (MITTAL et al., 2013). Além disso, é interessante que estudos químicos mais aprofundados sobre essas plantas sejam capazes de identificar e diferenciar os componentes benéficos ao processo cicatricial, daqueles deletérios, de modo a determinar uma formulação de futuros produtos comerciais, mais seguras e efetivas (FERREIRA; PINTO, 2010).

Deve ser levado em consideração o fato de que os fitoterápicos possuem as mesmas características de um vegetal, ou seja, sazonalidade, alterações de composição em decorrência de solo, clima, e outros fatores ambientais. Essas 
propriedades dificultam a homogeneidade, e a padronização dos produtos farmacêuticos criados a partir dessas plantas (GOBBO-NETO; LOPES, 2007).

\section{CONSIDERAÇÕES FINAIS}

A cicatrização de feridas é uma prática significativa na clínica veterinária, e o uso de fitoterápicos pode auxiliar nesse tratamento, tornando-o mais eficaz e menos dispendioso.

A Amazônia é conhecidamente uma região de grande biodiversidade, sendo parte desse arsenal constituído de plantas medicinais, de uso corriqueiro entre as populações tradicionais.

O desenvolvimento dos conhecimentos sobre dos fitoterápicos amazônicos como agentes cicatrizantes, em especial a Copaíba, pode auxiliar a produção futura de produtos terapêuticos alternativos, que venham a ser empregados em protocolos veterinários.

\section{REFERÊNCIAS}

ADIELE, L. C.; ADIELE, R. C.; ENYE, J. C. Wound healing effect of methanolic leaf extract of Napoleona vogelii (Family: Lecythidaceae) in rats. Asian Pacific Journal of Tropical Medicine, v. 7, n. 8, p. 620-624, 2014. Disponível em: <https://doi.org/10.1016/S1995-7645(14)60104-8>. doi: 10.1016/S19957645(14)60104-8

AKBIK, D.; GHADIRI, M.; CHRZANOWSKI, W.; ROHANIZADEH, R. Curcumin as a wound healing agent. Life Sciences, v. 116, p. 1-7, 2014 . Disponível em: <https://doi.org/10.1016/j.Ifs.2014.08.016>. doi: 10.1016/j.Ifs.2014.08.016

BOTELHO, J. R. S.; SANTOS, A. G.; ARAÚJO, M. E.; BRAGA, M. E. M.; GOMESLEAL, W.; CARVALHO JUNIOR, R. N.; MEIRELES, M. A. A.; OLIVEIRA, M. S. Copaíba (Copaifera sp.) leaf extracts obtained by CO2 supercritical fluid extraction: Isotherms of global yield, kinetics data, antioxidant activity and neuroprotective effects. Journal of Supercritical Fluids, v. 98, p. 167-171, 2015. Disponível em: <https://doi.org/10.1016/j.supflu.2014.12.006>. doi: 10.1016/j.supflu.2014.12.006

BUDOVSKY, A.; YARMOLINSKY, L.; BEN-SHABAT, S. Effect of medicinal plants on wound healing. Wound Repair and Regeneration, v. 23, n. 2, p. 171-183, 2015. Disponível em: <https://doi.org/10.1111/wrr.12274>. doi: 10.1111/wrr.12274

DIAS, F. G. G.; CASEMIRO, L. A.; MARTINS, C. H. G.; DIAS, L. G. G. G.; PEREIRA, L. F.; NISHIMURA, L. T.; SOUZA, F. F.; HONSHO, C. S. Endodontics pastes formulated with copaiba oil: action on oral microbiota and dentin bridge formation in dogs. Ciência Rural, v. 45, n. 6, p. 1073-1078, 2015. Disponível em: $<$ https://www.researchgate.net/publication/277975634_Endodontics_pastes_formulat ed_with_copaiba_oil_Action_on_oral_microbiota_and_dentin_bridge_formation_in_d ogs >. doi: $10.1590 / 0103-84 \overline{78}$ cr20141284

DIAS-DA-SILVA, M. A.; PEREIRA, A. C.; MARIN, M. C. C.; SALGADO, M. A. C. The influence of topic and systemic administration of copaiba oil on the alveolar wound healing after tooth extraction in rats. Journal of Clinical and Experimental 
Dentistry, v. 5, n. 4, p. 169-173, 2013. Disponível em: <https://doi.org/10.4317/jced.51104>. doi: 10.4317/jced.51104

DORAI, A. A. Wound care with traditional, complementary and alternative medicine. Indian Journal of Plastic Surgery, v. 45, n. 2, p. 418-424, 2012. Disponível em: <https://doi.org/10.4103/0970-0358.101331>. doi: 10.4103/0970-0358.101331

EPSTEIN, F.; SINGER, A.; CLARK, R. Cutaneous wound healing. The New England Journal of Medicine, v. 341, n. 10, p.738-746, 1999. Disponível em: <https://doi.org/10.1056/NEJM199909023411006>.

10.1056/NEJM199909023411006

ESTEVÃO, L. R. M.; MEDEIROS, J. P.; BARATELLA-EVÊNCIO, L.; SIMÕES, R. S.; MENDONÇA, F. S.; EVÊNCIO-NETO, J. Effects of the topical administration of copaiba oil ointment (Copaifera langsdorffii) in skin flaps viability of rats. Acta Cirúrgica Brasileira / Sociedade Brasileira Para Desenvolvimento Pesquisa Em Cirurgia, v. 28, n.12, p. 863-869, 2013. Disponível em: <https://doi.org/10.1590/S0102-86502013001200009>. doi: 10.1590/S010286502013001200009

FERREIRA, V. F.; PINTO, A. C. A fitoterapia no mundo atual. Química Nova, v. 33, n. $9, \quad$ p. $1829, \quad 2010 . \quad$ Disponível em: <http://www.scielo.br/scielo.php?script=sci_arttext\&pid=S0100$40422010000900001 \& \operatorname{lng}=e n \& n r m=i s o>$.

FORZZA, R.C. LEITMAN, P. M.; COSTA, A.; CARVALHO JR., A. A.; PEIXOTO, A. L.; WALTER, B. M. T.; et al. ; Introdução - síntese da diversidade brasileira. Catálogo de plantas e fungos do Brasil. Rio de Janeiro: Jardim Botânico do Rio de Janeiro, 2010. p. 21-42.

GHOSH, P. K.; GABA, A. Phyto-extracts in wound healing. Journal of Pharmacy and Pharmaceutical Sciences, v. 16, n. 5, p. 760-820, 2013. Disponível em: $<$ https://www.ncbi.nlm.nih.gov/pubmed/24393557>.

GOBBO-NETO, L.; LOPES, N. P. Plantas medicinais: fatores de influência no conteúdo de metabólitos secundários. Química Nova, v. 30, n. 2, p. 374-381, 2007. Disponível em: <http://www.scielo.br/scielo.php?script=sci_arttext\&pid=S010040422007000200026\&lng=en\&nrm=iso>.

KOBAYASHI, Y. T. S.; ALMEIDA, V. T.; BANDEIRA, T.; ALCÂNTARA, B. N.; SILVA, A. S. B.; BARBOSA, W. L. R.; SILVA, P. B.; MONTEIRO, M. V. B.; ALMEIDA, M. B. Avaliação fitoquímica e potencial cicatrizante do extrato etanólico dos frutos de Jucá (Libidibia ferrea) em ratos Wistar. Brazilian Journal of Veterinary Research and Animal Science, v. 52, n. 1, p. 34-40, 2015. Disponível em: <https://doi.org/10.11606/issn.1678-4456.v52i1p34-40>. doi: 10.11606/issn.16784456.v52i1p34-40

LEANDRO, L. M.; VARGAS, F. S.; BARBOSA, P. C. S.; NEVES, J. K. O.; DA SILVA, J. A.; VEIGA-JUNIOR, V. F. Chemistry and biological activities of terpenoids from 
copaiba (Copaifera spp.) oleoresins. Molecules, v. 17, p. 3866-3889, 2012. Disponível em: <https://doi.org/10.3390/molecules17043866>. doi: 10.3390/molecules 17043866

LIMA, C. S.; MEDEIROS, B. J. L.; FAVACHO, H. A. S.; SANTOS, K. C.; OLIVEIRA, B. R.; TAGLIALEGNA, J. C.; et al.,; Pre-clinical validation of a vaginal cream containing copaiba oil (reproductive toxicology study). Phytomedicine, v. 18, n. 12, p. 1013-1023, 2011. Disponível em: <https://doi.org/10.1016/j.phymed.2011.05.004>. doi: 10.1016/j.phymed.2011.05.004

MASSON-MEYERS, D.; ENWEMEKA, C. S.; BUMAH, V.; ANDRADE, T.; FRADE, M. A. Topical treatment with Copaifera langsdorffii oleoresin improves wound healing in rats. International Journal of Phytomedicine, v. 5, n. 3, p. 378-386, 2013. Disponível em: <https://doi.org/http://dx.doi.org/10.5138/ijpm.v5i3.1248>. doi: http://dx.doi.org/10.5138/ijpm.v5i3.1248

MAVER, T.; MAVER, U.; STANA KLEINSCHEK, K.; SMRKE, D. M.; KREFT, S. A review of herbal medicines in wound healing. International Journal of Dermatology, v. 54, p. 740-751, 2015. Disponível em: <https://doi.org/10.1111/ijd.12766>. doi: 10.1111/ijd.12766

MITTAL, A.; SARDANA, S.; PANDEY, A. Herbal boon for wounds. International Journal of Pharmacy and Pharmaceutical Sciences, v. 5, n. 2, p. 1-12, 2013. Disponível em: <http://www.ijppsjournal.com/Vol5lssue2/6379.pdf>.

PAZYAR, N.; YAGHOOBI, R.; RAFIEE, E.; MEHRABIAN, A.; FEILY, A. Skin wound healing and phytomedicine: a review. Skin Pharmacology and Physiology, v. 27, p. 303-310, 2014. Disponível em: <https://doi.org/10.1159/000357477>. doi: $10.1159 / 000357477$

PIERI, F. A.; SILVA, V. O.; VARGAS, F. S.; VEIGA JUNIOR, V. F.; MOREIRA, M. A. $S$. Antimicrobial activity of Copaifera langsdorffii oil and evaluation of its most bioactive fraction against bacteria of dog's dental plaque. Pakistan Veterinary Journal, v. 34, n. 2, p. 165-169, 2014. Disponível em: <http://www.pvj.com.pk/pdffiles/34_2/165-169.pdf>.

SANTOS, R. C. V.; ALVES, C. F. S.; SCHNEIDER, T.; LOPES, L. Q. S.; AURICH, C.; GIONGO, J. L.; BRANDELLI, A.; VAUCHER, R. A. Antimicrobial activity of Amazonian oils against Paenibacillus species. Journal of Invertebrate Pathology, v. $109, \quad$ n. $3, \quad$ p. 265-268, 2012. Disponível em: <https://doi.org/10.1016/j.jip.2011.12.002>. doi: 10.1016/j.jip.2011.12.002

SANTOS, M. R. A.; LIMA, M. R.; OLIVEIRA, C. L. L. G. Medicinal plants used in Rondônia, Western Amazon, Brazil. Revista Brasileira de Plantas Medicinais, v. 16, n. 3, p. 707-720, 2014. Disponível em: <https://doi.org/10.1590/1983084x/13_102>. doi: 10.1590/1983-084x/13_102

SILVA, J. K. R.; PINTO, L. C.; BURBANO, R. M. R.; MONTENEGRO, R. C.; GUIMARÃES, E. F.; ANDRADE, E. H. A.; MAIA, J. G. S. Essential oils of Amazon 
Piper species and their cytotoxic, antifungal, antioxidant and anti-cholinesterase activities. Industrial Crops and Products, v. 58, p. 55-60, 2014. Disponível em: <https://doi.org/10.1016/j.indcrop.2014.04.006>. doi: 10.1016/j.indcrop.2014.04.006

SILVA, P. F.; BRITO, M. V. H.; PONTES, F. S. C.; RAMOS, S. R.; MENDES, L. C.; OLIVEIRA, L. C. M. Copaiba oil effect on experimental jaw defect in Wistar rats. Acta Cirúrgica Brasileira, v. $30, \quad$ n. 2, p. 120-126, 2015. Disponível em: <https://doi.org/10.1590/S0102-86502015002000006>. doi: 10.1590/S010286502015002000006

SLATTER, D. H. Manual de cirurgia de pequenos animais. 3. ed. São Paulo: Manole, 2007.

STUPP, T.; FREITAS, R. A.; SIERAKOWSKI, M. R.; DESCHAMPS, F. C.; WISNIEWSKI, A.; BIAVATTI, M. W. Characterization and potential uses of Copaifera langsdorfii seeds and seed oil. Bioresource Technology, v. 99, n. 7, p. 2659-2663, 2008.

Disponível

em:

<http://www.sciencedirect.com/science/article/pii/S0960852407003860?via\%3Dihub> . doi: 10.1016/j.biortech.2007.04.051

VIEIRA, R. C.; BOMBARDIERE, E.; OLIVEIRA, J. J.; LINO, R. S.; BRITO, L. A. B.; JUNQUEIRA-KIPNIS, A. P. Influência do óleo de Copaifera langsdorffii no reparo de ferida cirúrgica em presença de corpo estranho. Pesquisa Veterinária Brasileira, v. 28, n. 8, p. 358-366, 2008. Disponível em: <https://dx.doi.org/10.1590/S0100736X2008000800002>. doi: 10.1590/S0100-736X2008000800002 